\title{
Hypersensitivity Pneumonitis Induced by Shiitake Mushroom Spores
}

\author{
Shigeru Matsui, Tsugio Nakazawa*, Yoshio Umegae and Masatomo Mori
}

\begin{abstract}
Hypersensitivity pneumonitis due to the inhalation of Shiitake mushroom spores was demonstrated in a 38-year-old woman. Symptoms of cough, nausea and malaise, and clinical findings of cyanosis, bibasilar crackles, reduced lung volumes, hypoxemia, leukocytosis, elevated ESR, positive C-reactive protein, and bilateral diffuse reticulonodular shadows on chest roentgenogram improved after the patient was removed from exposure. Alveolitis was demonstrated by transbronchial lung biopsy, as well as an increase in lymphocytes in bronchoalveolar lavage. Serum precipitins and specific IgG antibodies to an extract of Shiitake mushroom spores, but not to other common molds or mushroom body, were detected in serum. Provocative inhalation test with the extract of mushroom spores caused the same clinical symptoms and signs as experienced in the workroom. This is the first report of typical hypersensitivity pneumonitis induced by Shiitake mushroom spores. Mushroom spores as well as thermophilic actinomycetes must be considered a causative agents for mushroom worker's lung.
\end{abstract}

(Internal Medicine 31: 1204-1206, 1992)

Key words: alveolitis, mushroom worker's lung, occupational allergic disease

\section{Introduction}

Hypersensitivity pneumonitis has been described as an occupational hazard of mushroom workers. In 1967 Sakula reported four cases of mushroom-worker's lung (1). These workers developed respiratory symptoms resembling those seen in farmer's lung. Serologic tests showed precipitins to thermophilic actinomycetes $(1-3)$ or an extract of mushroom compost (3-5). There have been few cases in which the mushroom spores have been suggested to cause hypersensitivity pneumonitis among mushroom workers $(6-8)$. However, none proved that Shiitake mushroom spores induced hypersensitivity pneumonitis.

The edible Shiitake mushroom is cultivated indoors year round in Japan. Oak wood logs are used instead of usual compost or wood chips. The pasteurized spawn of Shiitake mushroom are sown outdoors. The Shiitake mushrooms are grown on the surface of oak wood logs, in small closed buildings, kept at a suitable temperature and humidity. When the mushrooms are fully grown, the cultivating rooms are filled with mushroom spores. The size of these oval spores is 4 to $8 \mu \mathrm{m}$. Workers can inhale the spores and may also be exposed to other hazards, such as inhaling various kinds of mold spores or other contaminants. Indoor cultivation methods result in less contaminants compared to the outdoor method, as compost is not used and molds do not grow as readily.

\section{Case Report}

In April 1972, a 22-year-old woman started work cultivating Shiitake mushrooms. Six years later, she reported nausea at work. The symptom disappeared when she did not work in the building. In August 1987, she complained of cough, nausea, and malaise several hours after work. These symptoms became so marked that she consulted the clinic of our hospital. There was no history of smoking, pets, previous respiratory illness, or travel outside Japan. Auscultation of her chest revealed bilateral bibasal crackles. Examination of the extremities showed slight cyanosis but no clubbing. A chest roentgenogram demonstrated diffuse reticulonodular shadows throughout both lungs. Pulmonary function studies showed the forced vital capacity (FVC) to be $1,570 \mathrm{ml}$ $(60 \%$ of predicted), the forced expiratory volume in one

From the First Department of Internal Medicine, and *the College of Medical Care and Technology, Gunma University, School of Medicine, Macbashi

Received for publication December 7, 1991; Accepted for publication July 24, 1992

Reprint rcquests should be addressed to Dr. Shigeru Matsui, the First Department of Intcrnal Mcdicine, Gunma University, School of Medicine, 3-39-15, Showa-machi, Maebashi, Gunma 371, Japan 
second $\left(\mathrm{FEV}_{1.0}\right)$ to be $1,570 \mathrm{ml}$ and $\mathrm{FEV}_{1.0} / \mathrm{FVC}$ ratio to be 1.00. Arterial blood gas measurements on room air were: $\mathrm{pH}, 7.42 ; \mathrm{PCO}_{2}, 34 ; \mathrm{PO}_{2}, 66$. The leukocyte count was 11,400 . The erythrocyte sedimentation rate (ESR) was increased, and C-reactive protein was strongly positive. She was advised to avoid working in the mushroomcultivating buildings and her condition improved. However, on return to her former work, the symptoms appeared again. In February 1988, she was referred to our hospital for investigation.

On admission, most of the previously documented abnormal findings had improved. The reticulonodular infiltrates on chest roentgenogram had disappeared. However, the serum level of total IgG was slightly increased. Mantoux reaction using PPD was negative. Histologic findings of the lung obtained by transbronchial lung biopsy (TBLB) revealed alveolitis compatible with hypersensitivity pneumonitis; thickening of alveoli due to infiltration of plasma cells, lymphocytes and macrophage-like cells. Bronchoalveolar lavage (BAL) demonstrated the total cell count to be $1.1 \times$ $10^{7}$. The differential showed lymphocytes, $89 \%$ (T-4, $33 \% ; \mathrm{T}-8,50 \%$; T-4/T-8, 0.6) macrophages, $10 \%$ and granulocytes, $1 \%$.

Evaluation of the patient's serum by agar gel doublediffusion tests with a panel of common antigens was negative (9). Precipitins against Shiitake mushroom spore extract were detected, but not against Micropolyspora faeni, Thermoactinomyces vulgaris, Tricosporon cutaneum (antigen of Japanese summer type hypersensitivity pneumonitis), other molds antigens commonly associated with hypersensitivity pneumonitis, or against Shiitake mushroom body extract (Table 1).

Serum from the patient's husband, who has also

Table 1. Precipitating Antibodies by Ouchterlony's Method and Specific IgG Antibodies by RFIA Method in Serum

\begin{tabular}{lccl}
\hline & Precipitin & Specific IgG Antibody \\
\hline Shiitake spore extract & + & $1093^{*}$ & RFU \\
Micropolyspora faeni & - & 355 & RFU \\
Thermoactinomyces vulgaris & - & 275 & RFU \\
Tricosporon cutaneum & - & ND & \\
Cryptostroma corticale & - & 362 & RFU \\
Pullularia pullulans & - & 364 & RFU \\
Candida albicans & - & ND & \\
Aspergillus fumigatus & - & ND & \\
Penicillim & - & ND & \\
Alternaria & - & ND & \\
Cladosporium & - & ND & \\
Pigeon droppings & - & ND & \\
Shiitake body extract & - & ND & \\
\hline
\end{tabular}

RFIA: release fuoroimmunoassay, + Precipitating lines found, - No precipitating lines found, RFU: fluorescence value determined by the release fluoroimmunoassay for specific IgG antibodies, * Cut off RFU value of the normal control subjects was $600, \mathrm{ND}$ : Not Done.

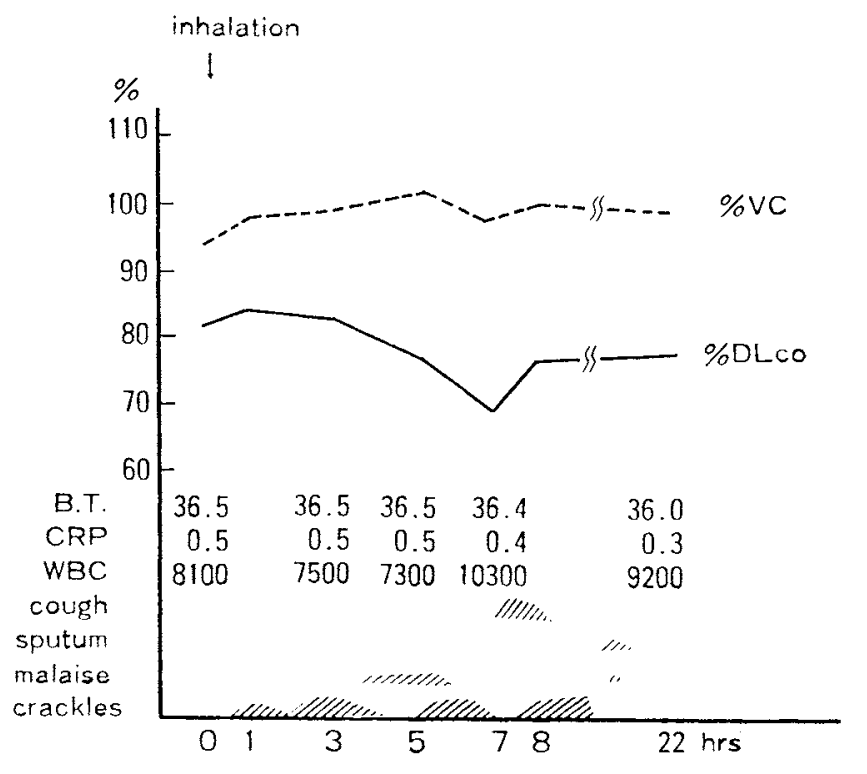

Fig. 1. Results of provocative inhalation test with an extract of Shiitake mushroom spores. Results of the normal control subjects were negative.

worked in the mushroom buildings but in whom no illness had developed, contained no precipitins to the Shiitake mushroom spore extract.

The release fluoroimmunoassay (RFIA) method (10), a modification of the ELISA method, was used for the determination of specific $\operatorname{IgG}$ antibodies and specific $\lg E$ antibodies. The level of serum IgG antibodies to Shiitake mushroom spore extract was two times higher than levels of the normal control subjects. However, the patient did not have elevated levels of serum IgG antibodies to $M$. faeni, T. vulgaris, Cryptostroma corticale and Pullularia pullulans. In contrast, specific IgE antibody to the spore extract was not detected.

A provocative inhalation test using $0.02 \mathrm{mg}$ protein of the mushroom spore extract was performed (Fig. 1). Four hours after allergen inhalation, the patient complained of malaise. Seven hours later, cough developed as well as a leukocytosis. At this time, a decrease in $\%$ DLco and an increase in crackles in her lower chest were documented. There appeared to be no change on chest roentogenogram, but bilateral nodular densities were documented in both upper lobes on chest CT.

\section{Discussion}

The diagnosis of hypersensitivity pneumonitis caused by an unknown organic agent should include a number of criteria in order to identify the antigen. In this case these criteria included (i) exposure to sufficient Shiitake mushroom spore antigen of a size $(4-8 \mu \mathrm{m})$ small enough to be a potential cause of hypersensitivity pneumonitis; (ii) cough, nausea and malaise developing several hours after inhalation of the spores, and accompanied by 
leukocytosis, elevation in ESR and C-reactive protein, and increase of $\mathrm{IgG}$; (iii) the presence of bibasilar crackles; (iv) a diffuse reticulonodular shadow on chest roentgenogram; (v) pulmonary function tests demonstrating a reduced vital capacity, a decrease of percent carbon monoxide diffusing capacity, and hypoxemia without evidence of airway obstruction; (vi) the presence of serum precipitins and specific IgG antibodies to the spores; (vii) a positive provocative inhalation test; (viii) histologic findings by TBLB, of alveolitis compatible with hypersensitivity pneumonitis; (ix) improvement in clinical symptoms and signs on avoidance of exposure of the spores; $(\mathrm{x})$ a marked increase of T-lymphocytes, especially $\mathrm{T}-8$, in BAL fluids.

The information obtained in this case fulfill all of these criteria. Therefore, the Shiitake mushroom spore is believed to be the allergen causing hypersensitivity pneumonitis. This case represents a new occurrence of hypersensitivity pneumonitis induced by Shiitake mushroom spores. There are several reports concerning hypersensitivity pneumonitis among mushroom workers $(1-8)$. Offending allergens in these reports were mostly organic dusts containing thermophilic actinomycetes arising from the compost where the mushrooms were grown $(1-5)$. Our previous reports suggested that some types of mushroom spores can cause hypersensitivity pneumonitis $(7,8)$. In this case, precipitins and specific IgG antibodies were detected only to mushroom spore extract but not to other common molds or mushroom body extract. Also, inhalation with spore extract provoked typical symptoms and signs of hypersensitivity pneumonitis. The reason why mushroom spores induced the disease seems to be due to indoor cultivation. In this method, spores will stagnate in the cultivating room and can easily be inhaled by the workers. Since mushroom spores as well as molds can provoke occupational hypersensitivity pneumonitis, mushroom spores must be considered as a causative agent of hypersensitivity pneumonitis in indoor mushroom cultivation.

Acknowledgments: The authors are grateful to Dr. P.M. O'Byrne of the Department of Medicine, Faculty of Health Sciences, McMaster University, Hamilton for his review and comments; to Prof. K. Sato, College of Medical Care and Technology, Gunma University, Japan, for her assistance in the determination of specific $\mathrm{IgG}$ antibodies and spccific IgE antibodies, and to Dr. H. Fukuyama who referred this patient for study.

\section{References}

1) Sakula A. Mushroom-worker's lung. Br Med J 3: 708, 1967.

2) Craig DB, Donevan RE. Mushroom-worker's lung. Can Med Assoc J 102: 1289, 1970.

3) Johnson WM, Kleyn JG. Respiratory disease in a mushroom worker. J Occup Med 23: 49, 1981.

4) Jackson E, Welch KME. Mushroom worker's lung. Thorax 25: 25, 1970.

5) Chan-Yeung M, Grzybowski S, Schonell ME. Mushroom worker's lung. Am Rev Respir Dis 105: 819, 1972.

6) Noster U, Hausen BM, Felten G, Schulz KH. Mushroom worker's lung caused by inhalation of spores of the edible fungus Pleurotus Florida. Dtsch Med Wochenschr 101: 1241, 1976.

7) Nakazawa $T$, Kanctani K, Umegae Y, Fueki R, Kobayashi S. Mushroom worker's lung due to inhalation of spores of the cortinus Shiitake. Nihon Kyobu Rinsho 40: 934, 1981 (in Japanese).

8) Nakazawa T, Tochigi T. Hypersensitivity pneumonitis due to mushroom (Pholiota nameko) spores. Chest 95: 1149, 1989.

9) Ouchterlony O. Diffusion-in gel methods for immunological analysis. Prog Allergy 6: 30, 1962.

10) Hemmilia I. Fluoroimmunoassays and immunofluorometric assays. Clin Chem 31: 359, 1985. 